\title{
A Review of Extrusion-Based 3D Printing for the Fabrication of Electro- and Biomechanical Sensors
}

\author{
Martijn Schouten Student-Member, IEEE, Gerjan Wolterink, Alexander Dijkshoorn Student-Member, IEEE, \\ Dimitrios Kosmas, Stefano Stramigioli Fellow, IEEE and Gijs Krijnen Senior-Member, IEEE
}

\begin{abstract}
In this review paper, we focus on the 3D printing technologies that consist of the extruding of fluid material in lines to form structures for electro- and biomechanical applications. Our paper reviews various 3D print technologies, materials, sensing technologies and applications of extrusion-based 3D printing. We also discuss how to overcome some of the challenges with 3D printed sensors, such as the anisotropy of the conductors as well as the drift and nonlinearity of the materials.
\end{abstract}

Index Terms-3D printed Sensors, Additive Manufacturing, Fused Deposition Modelling, Direct Ink Writing, Embedded Sensing, Flexible Strain Sensors, Fiber encapsulation.

\section{INTRODUCTION}

Weller et al. [1] have identified four aspects of 3D printing that enable it to compete with traditional manufacturing. These aspects are the versatility of the manufacturing method, free customization, free product design complexity and the reduction of assembly. The versatility and customization of the technique make the technique extremely well suitable in for example biomedical and research applications, where often small volumes of custom parts of many types are needed. The free product design complexity and the reduction of assembly introduce a huge opportunity for sensing, increasing the feasibility of large complex networks of sensors. Other authors [2], [3] also concluded that additive manufacturing can compete with traditional manufacturing in specific situations. Therefore, it is no surprise that a lot of research on a wide range of 3D printed sensors [4], [5], [6] has been done over the last couple of years.

The most basic form of 3D printing consists of extruding fluid material in lines, actually track elements or 'traxels' [7], which solidifies after being deposited. Since this form of 3D printing is comparatively simple, it is also the most affordable and accessible [8], [9]. Furthermore, the technology can be relatively easily expanded to include multiple materials (section [II-B). For these reasons, this review is limited to extrusion-based printing.

This paper will give an overview of the different printing technologies, materials, sensing technologies and applications that can be used for extrusion-based 3D printed sensors. The

This work was sponsored by the SoftPro project, funded by the European Union's Horizon 2020 Research and Innovation Programme under Grant Agreement No. 688857; the PortWings project, funded by the European Research Council under Grant Agreement No. 787675 and the Wearable Robotics project, funded by the NWO-TTW Perspectief Programma.

The authors are with the Robotics and Mechatronics Department of the University of Twente, Enschede, the Netherlands. Gerjan Wolterink is also with the biomechanical signals and systems group of the University of Twente

Manuscript received 31-08-2020; revised 23-10-2020. paper distinguishes itself by also discussing how to overcome some of the intrinsic limitations of 3D printed sensors, such as the anisotropy of the conductors and nonlinearity of the materials. Finally, it also discusses the different techniques that can be used to switch between different materials.

\section{Suitable TeChNOlOGiES FOR 3D PRINTED SENSORS}

Most sensor designs consist of multiple types of materials. Thus, a 3D printer that can print multiple types of materials, such as conductors, dielectrics, flexible and stiff materials, is key to the fabrication of sensors to 3D printing parts with integrated sensors.

\section{A. Extrusion systems}

With each additional extrusion technique that becomes available, a whole new range of materials can be printed. This section gives some examples of the different extrusion techniques currently available.

1) FDM: Fused deposition modeling (FDM) is an additive manufacturing technology where a 3D-object is built up by melting and depositing a thermoplastic material through a nozzle on a building platform where it solidifies. This extrusion method is widely preferred due to its open-source and low cost nature [4]. The raw materials are in the form of filaments which allow the materials to be easily pushed through the hotend by an extruder. FDM offers a wide variety of materials with different properties ranging from stiff to flexible [4], [10]. However, there are limitations on which materials can be printed together due to differences in melting temperatures, shrinkage, chemical composition and wetting behavior.

In general two types of FDM system can be distinguished.

a) Bowden: In the Bowden setup, the extruder is decoupled from the moving hot-end and the filament is transported using a Bowden tube. Since the extruder is decoupled from the moving hot-end, the print head can be smaller and lighter compared to the direct-drive setup. However, in the distance between the extruder and the hot-end, flexible filament is easily compressed and may incur stiction and friction forces on contact with the tube-wall. This leads to inconsistencies in the filament flow, making the Bowden setup less suited for flexible filaments. However, the performance might be improved by using a Bowden tube with tight tolerances [11].

b) Direct-drive: In the direct-drive setup, the extruder is placed on top of the print head, leading to a short straight filament path between the extruder and the hot-end. To increase the performance for flexible filaments even further, the 


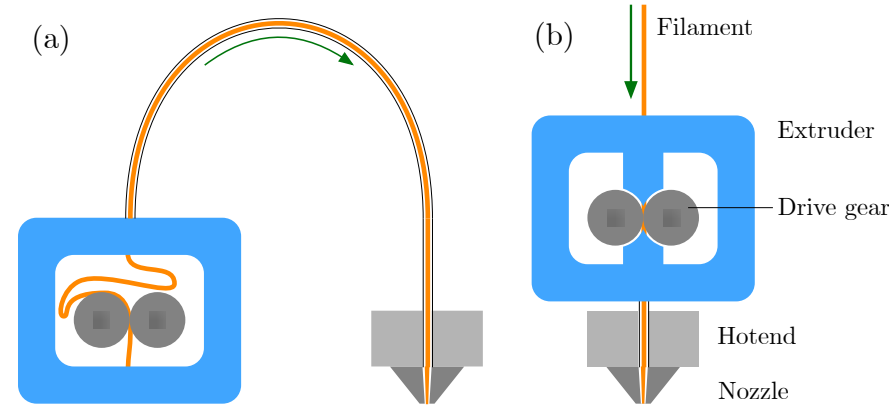

Fig. 1. The filament can be transported in two possible ways to the hotend. By a Bowden setup (a), where the extruder is decoupled from the hotend, and a direct-drive (b), where the extruder is mounted on the hot-end. Fully constraining the filament path (as shown right) prevents tangling of the filament.

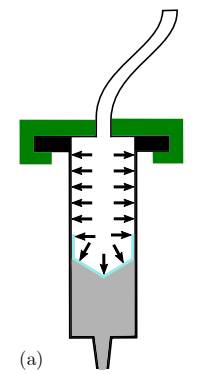

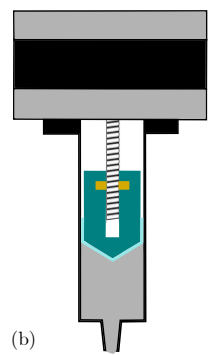

Fig. 2. Illustration of various direct ink writing extruder techniques; (a) Pneumatic (b) Syringe (c) Progressive cavity

extruder should have a fully constrained path between the drive gear and the hot-end to prevent the filament from escaping from the extruder (see Figure 1).

2) Direct ink writing: Direct ink writing is a technique where ink or paste is deposited through a needle to create or to add functionality to objects. Direct ink writing can be used to print inks for which the polymerization is catalyzed by heat or light. The solid content in the final object can be higher than for FDM and therefore, materials with properties more similar to that of solid content inside the ink such as metals [12], ceramics [13] or wood [14] can be deposited. For the deposition of inks during the $3 \mathrm{D}$ printing process, several techniques exist (see Figure 2).

a) Pneumatic: Pneumatic extruders use a high precision pressure generator to precisely control the pressure inside a syringe. The syringe is connected through a flexible tube to the dispenser, and only the syringe is moved [12], [15], [16]. To set the volumetric flow rate as required by the $3 \mathrm{D}$ printing process, the pressure should be adjusted for the viscosity of the ink and the hydraulic resistance of the nozzle.

b) Syringe: Syringe extruders use a lead screw to translate the rotation of a stepper motor and an optional transmission into the displacement of the plunger of a syringe [13], [17], [18]. They provide a low-cost solution, but the dynamics of the system are strongly affected by any air inside the syringe. In order to achieve good control over the volumetric flow rate, a syringe without air should be used. Filling a syringe without air may require additional steps in case the ink is highly viscous, since any bubbles will move rather slow
TABLE I

OVERVIEW DIRECT INK WRITING

\begin{tabular}{l|lll} 
& $\begin{array}{l}\text { Volumetric } \\
\text { flow rate }\end{array}$ & $\begin{array}{l}\text { Bubble } \\
\text { sensitive } \\
\text { dynamics }\end{array}$ & $\begin{array}{l}\text { Dead } \\
\text { volume }\end{array}$ \\
\hline Pneumatic & No & No & $<84 \mu \mathrm{L}[23]$ \\
Syringe & Yes & Yes & $<84 \mu \mathrm{L}[23]$ \\
Progressive cavity & Yes & No & $3 \mathrm{~mL} \mathrm{[22]}$
\end{tabular}

through the viscous liquid [19].

c) Progressive cavity: Progressive cavity extruders use a helically shaped rotor and flexible stator to achieve the fast responding, volumetric, non-pulsating flow, which is required by the $3 \mathrm{D}$ printing process [20], [21]. Because all the cavities need to be filled with ink before the extruder can be used, the dead volume of this method is larger than that of the other two methods. For a Viscotec Viprohead 3 progressive cavity extruder, the dead volume is $3 \mathrm{~mL}$ [22] while a syringe may have less than $84 \mu \mathrm{L}$ dead volume [23]. This makes this method less suitable for very expensive functional inks.

As shown in Table [1, a pneumatic extruder might be considered if a single ink with a constant viscosity is to be extruded at a constant volumetric flow rate. A syringe extruder can be a low-cost solution in case low viscosity inks are used, where any air can be easily removed. A progressive cavity extruder is an excellent solution in case the used inks are relatively low-cost due to the loss of ink in the relatively large dead volume.

3) Embedded fibers: Recently, the opportunity to embed fibers in FDM printing has significantly improved the mechanical performance of FDM printed parts [24]. Also, with this kind of technology, fibers or wires can be embedded during fabrication for the sake of their electrical properties. Three main methods exist for 3D printing with embedded fibers:

a) Fiber placement: is a technique in which fibers or wires are laid onto the surface in between the printing of layers. The fiber placement can be done by hand [25], ironed into the material with a separate nozzle [26] or roller [24] during fabrication or even placed by hand after fabrication [27].

b) Fiber co-extrusion: is the technique in which a wire of fibers is extruded together with the molten matrix material. This can be done through the same nozzle [28], [29], [30] or through a different nozzle directly into the molten material (also called fiber encapsulation) [31], [32]. Single nozzle printers limit the control over fiber placement, which is the reason most machines have separate nozzles or separate the control of fiber co-extrusion and plastic extrusion.

c) Embedding wires after printing: can be performed by means of localized ultrasonic or Joule heating [33], [34], [35]. The use of this technique is limited since wires can only be embedded close to the surface and in limited geometries.

Embedding fibers poses several challenges for fabrication. For example, the minimum layer thickness is dictated by the diameter of the used fiber with co-extrusion, whereas the diameter combined with the mechanical properties of the fiber limit the bending radius that can be achieved for placement [36]. A major limitation is posed by the layer-wise 


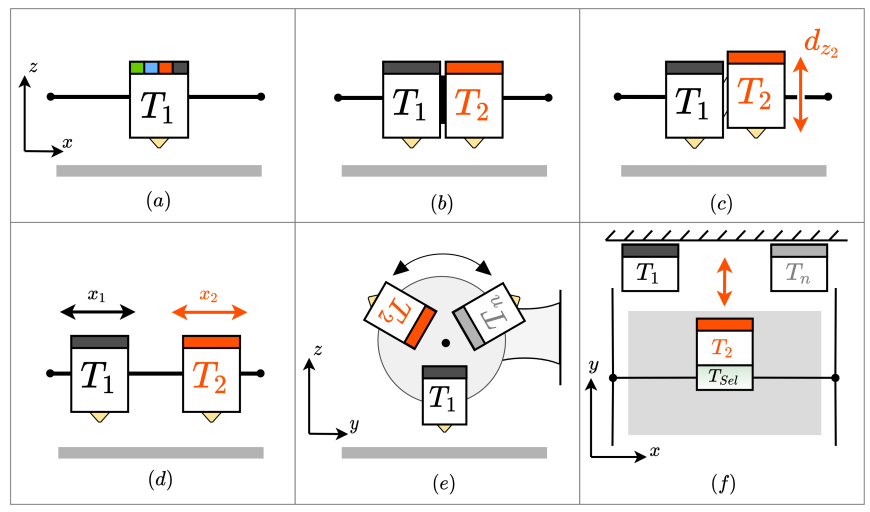

Fig. 3. Different material switching systems. (a) Single-nozzle (b) Stationarynozzle (c) Lifting-nozzle (d) Independent multi-toolhead (e) Rotary multitoolhead (f) Toolchanger multi-toolhead

fabrication of FDM, since fibers are strictly printed in single layers, producing anisotropic properties [26]. Finally, it is difficult with $3 \mathrm{D}$ printing to achieve high fiber volume fractions $(>50 \%)$ and to minimize voids between fibers [24].

\section{B. Material switching systems}

In many cases, the fabrication of sensors requires multiple materials. In order to print these materials with the same printer, the printer needs to be capable to switch between the materials.

1) Challenges: The switch between different materials however, is not trivial, and several challenges exist.

a) Contamination: When switching materials, it is hard to remove all the material from the nozzle. Therefore when a new material is inserted, it will often be contaminated with the previous material. As a consequence, each time a material change takes place, large amounts of filament have to be purged as means to remove old residue from the filament path, resulting in substantial waste blocks [37].

b) Tool interference: Often it is not possible to completely turn off the extrusion of the nozzles immediately and, as a consequence, some material may ooze out the inactive print-heads for a while. Furthermore, if other tools than the active tool-head are moving during printing, they might physically deform the deposited filament.

c) Added Inertia: Adding multiple tool-heads to a printing system can result in a large mass to be accelerated, especially when direct-drive print-heads are used. If the printing process requires this mass to be accelerated rapidly, this will impose tough constraints on the mechanics of the printer, increasing the cost of the printer. Therefore the challenge is to limit the mass that is moving in the printing directions ( $x$ and $y$ ), e.g. by using a (sub-optimal) Bowden setup or moving the bed instead of the nozzles.

d) Alignment challenges: Often it is challenging to obtain sufficient repeatability of the system so that the different tools are aligned to each other and stay aligned throughout the printing process.
2) Systems: To overcome these challenges, several nozzle changing systems are in use (see Figure 3).

a) Single-nozzle: In this adaptation multiple filaments are individually fed into a single-nozzle [38], [39] (see Figure 3 a). The material switching process is handled by the external module. A pre-feeder configuration selects which filament should be inserted into the nozzle filament path. This configuration also makes it possible to have multiple filaments mixed in a common chamber within the heating block [40], [41].

Due to the single heating element, the contamination risk is high. Moreover, for both the switching and the mixing systems, the available material combinations are limited because some of the contamination might disintegrate under the printing conditions of the other materials.

b) Stationary-nozzles: The simplest arrangement for a separated multi-extrusion process can be obtained from a sideby-side placement of two or more distinct extrusion systems, allowing materials to be loaded simultaneously [42], [43] (see Figure 3p). Because it is impossible to get all nozzles perfectly at the same height, there will always be one active nozzle for which an inactive nozzle touches the currently printing layer. Every nozzle can be operated at different temperatures, providing the possibility to work with a wider range of materials. The fixed-nature of the extruders leads to tool interference, alignment as well as oozing issues. These effects are even more evident in configurations with more than two nozzles.

c) Lifting-nozzle: To solve tool interference issues caused by all the nozzles being at the same height, in some printers [44], [45], [46] the active nozzle is slightly lowered relative to the other nozzles, effectively providing a safe distance between the idle nozzle and the printed part ( see Figure 3e).

d) Multi-toolhead: A multitude of different implementations exist which have in common that they have multiple toolheads which can be used more or less independently.

The IDEX (Independent Dual EXtrusion) system employs at least two toolheads that move simultaneously and independently from each other [47], [48], [49] (see Figure 3d). Most often this configuration is seen with the toolheads decoupled along the $x$ axis.

In a rotary multi-material configuration, the printer is equipped with a turret mechanism incorporating an $n$ number of extrusion systems placed (fixed) across the turret's circumference (see Figure 3 ). While unlocked the turret rotates until the selected tool is in the operating position (perpendicular to the printing platform) and then it is either locked [50] or an optical (optical) feedback mechanism [37] is applied to eliminate any rotation.

A tool-changer configuration most often is based on the so-called coreXY kinematics [51] motion system [52]. Each extruder is configured as a swappable tool and is parked in a pre-defined position on the frame (see Figure 3f). During a tool change, the tool-base gets located in-front of a parked tool and the switching mechanism locks the tool in the base. 
TABLE II

OVERVIEW MATERIAL SWITCHING SYSTEMS

\begin{tabular}{|c|c|c|c|c|}
\hline & $\begin{array}{l}\text { Single } \\
\text { nozzle }\end{array}$ & $\begin{array}{l}\text { Stationary } \\
\text { nozzles }\end{array}$ & $\begin{array}{l}\text { Lifting } \\
\text { nozzles }\end{array}$ & $\begin{array}{l}\text { Multi- } \\
\text { toolhead }\end{array}$ \\
\hline Contamination & Yes & No & No & No \\
\hline Tool Interference & No & Yes & No & No \\
\hline Added Inertia & No & Yes & Yes & No \\
\hline Alignment Challenges & No & Yes & Yes & Yes \\
\hline
\end{tabular}

With 3D printed sensors in mind, both the single material and stationary systems fall short of the task due to the contamination and tool interference issue, respectively. The liftingnozzle system provides an elegant solution. However, for many material systems, the inertia issue may add a limitation towards printing speed and acceleration settings. In this case, a multitoolhead system may be a better solution (see Table II).

\section{MATERIALS}

The aforementioned extrusion systems can be used to print a wide range of structural materials, ranging from very flexible [16] to very stiff [53]. In order to make networks of 3D printed sensors, often both conductive and sensing materials are used. The conductive material is then primarily used to electrically interface the sensors.

\section{A. Conductive materials}

The ability to 3D print conductors is fundamental to the fabrication of parts with integrated sensors. The conductors might not only be used to fabricate piezoresistive or capacitive sensors but also allow for wiring inside the printed structure to connect the sensors to the read-out electronics.

1) Filaments: A common method to directly print with the conductive material in FDM printing is by using a filament made of a conductive polymer composite, e.g. a thermoplastic base material blended with carbon-based materials, such as carbon black, graphene, graphite or carbon-nanotubes. These materials are low-cost, readily available and chemically stable [63], [64], [65], [66], [67]. The material is very well suited for the fabrication of truly three-dimensional conductors, where multiple layers of the 3D printed structure are connected. High-filler concentrations will decrease the strength of the materials due to the loss of particle-matrix adhesion [68]. Furthermore, these materials obtain conduction through percolation networks and, therefore, the effect of the filler concentration on the resistivity diminishes with increasing concentration [69], [70], [71]. At last, because of the composite nature of the materials, they often exhibit the piezoresistive effect, which is discussed in section III-B1. Table III lists the limited commercially available conductive polymer composite filaments.

2) Inks: The inks that can be used for direct ink writing are often specifically developed for a given process, e.g. for ink-jetting or screen printing. Inks for jetting always have a low viscosity and small particle size (1-30 mPa s, while screen printing inks generally have a much higher viscosity (1000$10000 \mathrm{mPas}$ [ [72]. Since a high solid content increases the viscosity of the ink [73], it can be higher for a screen print ink than for a jetting ink for a given solvent. The viscosity and the wetting behavior of the used ink determine how the ink will behave in combination with other materials after printing.

In most common conductive inks silver particles are used (see Table IV). In applications where biocompatibility is a requirement, PEDOT:PSS based inks are often used [74], [75]. The inks come in varying degrees of flexibility, ranging from non-flexible, flexible and even stretchable. Some inks require either a UV or a thermal curing step. For 3D printing applications the stability of the ink is often important, since it is unpractical if ink components separate inside the extruder between prints or even during the print. Some examples of commercially available silver inks are shown in Table IV

3) Fibers: Several types of fibers and wires can be used as current carrying traxels for sensing applications. Based on the electrical and mechanical properties, important distinctions can be made. Copper wires can be used for carrying large currents because of the high conductivity of copper, which for wires equals the bulk conductivity [35]. Parts with embedded carbon fiber have already been printed with a resistivity of around $3.7 \times 10^{-4} \Omega \mathrm{m}$ [26]. Carbon fiber can be printed as dry fibers. However, more often, carbon fiber is used in a socalled prepreg, where a bundle of dry fibers is impregnated with a polymer and shaped as a filament beforehand [81]. A prepreg offers advantages for printing since dry carbon fibers are very brittle, difficult to handle and easily introduce void formation and poor adhesion during printing [24], [81]. On the other hand, dry fibers with co-extrusion give more flexibility for choosing the fiber and matrix combinations. So copper wires can be used in case high currents or low resistance is required, where carbon fiber is mainly used for high yield strength and offers higher resistance.

4) Liquid metals: Another class of conductors that can be used to add functionality to 3D printed objects are liquid metals, like gallium indium (eGaIn) and Galistan (eGaInSn). These liquid metals can be added to the printed object using direct ink writing [82], [18] or afterwards by filling [83]. The metals have a low resistivity of $29 \mu \Omega \mathrm{cm}$ in case of Galistan [84], as well as a low viscosity of $(2.4 \mathrm{mPas}$ for Galistan [84]) and because the metal remains liquid it can be stretched, up to $200 \%$ without breaking [82]. It should be noted that liquid metals such as eGaIn corrode other metals and therefore, might cause damage to the printers in which they are used [85].

Which conductive material is most suitable depends on the application, as illustrated in Table V FDM filaments offer a low-cost solution for real 3D conductors. However, their conductivity is limited. Copper fibers, liquid metals and silver inks allow a much higher current density in stiff structures. Besides their high conductivity, stretchable silver inks and liquid metals also can be stretched up to multiple times their length.

\section{B. Sensing materials}

This section will give a short overview of $3 \mathrm{D}$ printable functional materials that can be useful in the fabrication of electro- and biomechanical sensors. 
TABLE III

OVERVIEW OF COMMERCIALLY AVAILABLE CONDUCTIVE MATERIALS FOR FDM PRINTING [54].

\begin{tabular}{llll}
\hline Name & Host & Doping & Volume resistivity [ $\Omega \mathrm{cm}]$ \\
\hline Proto-Pasta [55], [56] & PLA & Carbon black & $30(\mathrm{x}, \mathrm{y}) 115(\mathrm{z})$ \\
BlackMagic3D Conductive Graphene [57], [58] & PLA & Graphene and Graphite & 0.6 \\
Multi3D, Electrify [59] & Biodegradable polyester & Copper & 0.006 \\
PI-ETPU 95-250 Carbon Black [60] & TPU & Carbon black & $<300$ \\
EEL [61], [62] & TPU & Carbon black & $1.5 \times 10^{3}$
\end{tabular}

TABLE IV

EXAMPLES OF COMMERCIALLY AVAILABLE AG BASED CONDUCTIVE INKS

\begin{tabular}{lllll}
\hline Name & Curing & Stretchability & Viscosity $(\mathrm{mPas})$ & ${\text { Surface resistivity } \mathrm{m} \Omega \mathrm{sq}^{-1}}$ \\
\hline EMS CI-1036 [76], [77] & Thermal & Stretchable & $10^{4}$ & $10 @ 25 \mu \mathrm{m}$ \\
LOCTITE EDAG PD004A E\&C [78] & UV & Flexible & 800 & $6 @ 25 \mu \mathrm{m}$ \\
Electrolube SCP [79] & Thermal & Not specified & 70 & $6 @ 20 \mathrm{mg} \mathrm{cm}^{-2}$ \\
Dupont PE410 [80] & Thermal & Not Specified & $20-40$ & $5 @ 25 \mu \mathrm{m}$ and $130^{\circ} \mathrm{C}$
\end{tabular}

TABLE V

COMPARISON OF EXTRUDABLE CONDUCTORS

\begin{tabular}{|c|c|c|c|c|}
\hline & Filaments & Inks & Fibers & $\begin{array}{l}\text { Liquid } \\
\text { metals }\end{array}$ \\
\hline 3D interconnects & Easy & Difficult & Difficult & Moderate \\
\hline Conductivity & Poor & Good & Excellent & Excellent \\
\hline Stretchable & Yes & Yes & No & Yes \\
\hline
\end{tabular}

1) Piezoresistive materials: When a conductive material is strained, the resistance changes due to a change in diameter, length and specific resistivity. However, in most conductive polymer composites, the resistance change is bigger than expected by the geometrical effect due to the piezoresistive effect, resulting in a higher strain sensitivity. Conductive polymer composites show this piezoresistive effect due to the change of conductive paths in the polymer matrix under strain [86]. A major drawback of conductive polymer composites is the nonlinear resistance changes when the material is strained. Usually the resistance first decreases at small strains, due to optimal alignment of the conductive particles in the matrix, and subsequently increases at higher strain [64]. Furthermore, while the material is strained, there is a formation caused by polymer mobility and breakdown of conductive networks. At low strain rates these effects are in balance resulting in minimal resistivity changes, whereas at high strain rates the breakdown effect is more dominant [87], [88]. Furthermore, some of the used polymers, such as TPU, are viscoelastic themselves [89], which further increases the hysteresis and nonlinearity in the response of the piezoresistors. However, it might be possible to model these effects and compensate for them in software, as is discussed further in section VI. Besides conductive polymer composites, piezoresistive sensors could also be fabricated using conductive inks [17], [90], liquid metals [91], [92] or conductive fibers [29], [30].

2) Piezoelectric materials: A common piezoelectric material in 3D printing is PVDF. The material can directly be printed [93], and so can PVDF-ceramic composites [94]. The material can also be dissolved and used as ink, with the addition of a co-polymer [95] or ceramic particles [96]. Often the material is polarised after the fabrication process in order to increase the piezoelectric constant [97]. The formation of the piezoelectric $\beta$-crystal structure of PVDF can be enhanced by printing with a high voltage applied between the nozzle and the bed, as shown in [97], [98]. It should be noted that an effect similar to that of a piezoelectric material can be achieved using an electret, which can be 3D printed as well [99].

3) Magnetic materials: Both soft magnetic thermoplastics [100] as well as hard magnetic thermo-plastics [101] are commercially available. These thermo-plastics can be 3D printed and subsequently poled to produce a material with a remnant magnetisation [102], [103], [104]. However, the use of thermoplastics that are optimized for injection molding instead of FDM might result in brittle filament that is difficult to handle [105]. Specific magnetic thermoplastic composites can also be fabricated for specific research purposes [106], [107] on magnets and sensors. Another option is to include wires of ferromagnetic materials, such as nickel, for their magnetic properties [31].

Piezoresistive materials offer a simple and low-cost solution for adding pressure sensitivity to 3D printed parts. However, when the $3 \mathrm{D}$ printed piezoresistors are made using conductive polymer composites, they often show hysteresis and large nonlinearities. Piezoelectric and hard magnetic materials can be printed. However, for most applications, they need to be poled after or during printing.

\section{BONDING TECHNOLOGY}

Bonding wires to $3 \mathrm{D}$ printed sensors is important because of the significant influence of the connection on the resistance [108]. Despite this importance, it is a largely unexplored field and currently no standard exists. Table $\mathrm{VI}$ shows the most important methods used in literature. The $3 \mathrm{D}$ printing process specifically enables printing of connector geometries [109] and inserting electrical conductors during manufacturing [108]. The methods have large differences in contact resistance (from $1.6 \Omega$ [26] up to more than $1000 \Omega$ [108]). To bypass the high contact resistance, often four-wire measurements are used [6]. For connectors that are pushed in or onto the sample afterwards, the resistance strongly depends on the applied pressure [108], and therefore the contact resistance might influence the measurement. Especially for flexible and stretchable sensors, the connections are still challenging [110]. For connecting to carbon fiber, special steps need to be taken 


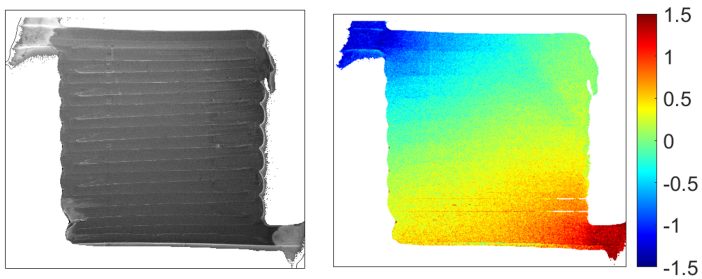

Fig. 4. VCSEM result (left) and the derived electric potential distribution (right) for a 3D printed sheet with in-plane anisotropic conduction [7] (C)[2020] IEEE)

in order to access the fiber and to remove the matrix [26], [30].

\section{ANISOTROPIC CONDUCTION IN 3D PRINTED MATERIALS}

The line-by-line, layer-per-layer FDM printing process creates anisotropic structures in 3D prints. These structures yield anisotropy in physical properties, which has been studied for e.g. the mechanical [120], thermal [121], magnetic [122] and electrical [123] domains. For the thermal and electrical properties, interfacial or interlayer contact resistance in the build direction in combination with the presence of voids are mentioned as the fundamental reasons for anisotropy [121], [123], [117]. This interlayer contact resistance strongly depends on raster angle, layer height and extrusion temperature [108], [124], [123]. For multiple printed layers, crossply infill patterns yield a lower resistivity, possibly because current paths more easily divert around areas of high local resistance [125]. The anisotropic resistivity can also be observed in-plane as a function of the raster angle (infill orientation) [108], [124]. A solution for reducing in-plane anisotropy could be to use different infill patterns, e.g. by means of a slicer that creates a maze-like (randomized) infill to obtain isotropic macroscopic properties [126]. On the other hand, the anisotropy can be purposely used for improvement of sensors, where inter-layer or inter-traxel resistance aids in sensitivity or directionality [63], [127]. For example, directional anisotropic strain sensors are printed with a meander-like infill, where the sensitivity and anisotropy can be tuned by means of the air gap between adjacent traxels, the infill density, and the build orientation [127].

\section{A. Characterisation of anisotropic conduction}

Modeling and measurements have been used to gain a better understanding of the anisotropic electrical properties. Hampel et al. [117] presented a model for anisotropic conduction, which assumes a different layer, intra-layer (inter-traxel) and inter-layer resistance due to improper fusion in different directions and demonstrated its use with a 1D example. MonteCarlo simulations have been used to study the effect of local resistance variations in resistor networks to represent 3D printed conductors [125]. FEM simulations are used to study anisotropy in all directions [123]. A small cell of traxel pieces represents the material with voids and layer bonding. Since voids, raster orientation and layer bonding are important for the anisotropic conductivity [124], these features need to be included in modeling. In previous work the authors therefore used the model of Hampel to simulate the in-plane anisotropy by including the inter-traxel resistance and meanders [7].

Impedance measurements are used for experimental characterization. In this way, inter-traxel and inter-layer resistance can be measured with rectangular samples in-between conductive plates in different orientations [108], [124], [123]. Research indicates that in-situ resistance measurements during printing can also be used for characterization of conductive prints [114]. In-plane anisotropy, however, can also be measured with a voltage contrast method in the scanning electron microscope (SEM) and with infrared (IR) thermography measurements via Joule heating [7]. Voltage contrast SEM (VCSEM) measures potential distributions since a difference in electric potential gives rise to contrast. In Figure 4 on the left, the contrast in an SEM image can be seen, whereas, on the right, the derived electric potential distribution is displayed. A small amount of anisotropic conduction is present in this case since the voltage distribution extends more along the traxels than across the traxel's interfaces [7]. During IR thermography measurements, an IR camera measures local temperature increases due to Joule heating, which is linked to the power dissipation. Hence, these two methods can be used to study the anisotropic conduction in sheet-like sensors [7].

\section{COMPENSATION METHODS}

\section{A. Drift compensation}

Drift is the generic name for slowly varying random changes, which can caused by, e.g., variations in temperature or humidity, unstable power supplies or $1 / \mathrm{f}$ noise [128]. In 3D printed sensors, these random errors might be caused by, for example, the positive temperature coefficient of the used piezoresistors [129], [130] or the creep of the used polymers [131], [132]. In order to compensate for this drift, a differential measurement might be used [133], or a separate temperature measurement can be used to compensate for this effect [134].

\section{B. Nonlinearity compensation}

Soft polymers have been shown to exhibit strong hysteresis [135], time-dependence, as well as cyclic softening [89]. It is shown that the effects of these nonlinearities are even more emphasized towards resistive sensors [136]. Compensation methods are then required before the application range of such sensors can be extended.

An overview of the most common techniques used in hysteresis modeling can be found in the work of Hassani et al. [138]. Focusing on FDM manufactured sensors, in [133] it is shown that a differential measurement significantly decreases the nonlinear response of 3D printed strain sensor. Additionally, towards the same sensor principle, in [137], [139] it is shown that it is possible to adapt a Power-law model so that the hysteresis is sufficiently captured under certain excitations.

Often hysteresis models are categorized based on the main method used (see Table VII). Operator-base describes the 
TABLE VI

OVERVIEW OF BONDING TECHNOLOGY FOR 3D PRINTED SENSORS.

\begin{tabular}{|c|c|c|c|}
\hline Bonding Technique & References & Advantage & Disadvantage \\
\hline Silver ink, paste and epoxy & {$[86],[26],[111],[28]$} & Low contact resistance & Can be mechanically weak \\
\hline Embedding wires by melting & $112],[63],[113]$ & Mechanically strong & Risk of deforming sensor \\
\hline Copper tape inserted during printing & $108,[114$ & Mechanically strong & High electrical contact resistance \\
\hline Connectors, headers and jumper wires & 6], 108, 109], 115 & Compatible with standard electronics & Contact resistance pressure dependent \\
\hline 3D printed snap-on connector & [10], [116] & Compatible with EMG hardware & Only suited for specific cases \\
\hline Screwed or bolted & 117], [66], [118] & Mechanically strong & Bulky \\
\hline Soldering & 119 & Low contact resistance & Only suited for e.g. electrodeposition \\
\hline
\end{tabular}

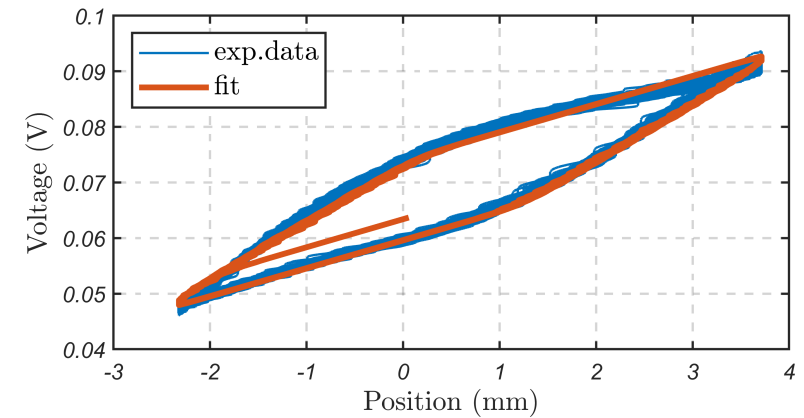

Fig. 5. 3D printed strain-sensor differential response and fit versus cyclic (sine-wave) excitation [137].

TABLE VII

CANDIDATE MODELS FOR CAPTURING NONLINEARITIES

\begin{tabular}{|c|c|c|}
\hline & $\begin{array}{l}\text { Rate } \\
\text { Dependency }\end{array}$ & $\begin{array}{l}\text { Base } \\
\text { method }\end{array}$ \\
\hline Preisach [140] & No & Operator \\
\hline Krasnosel'skii-Pokrovskii (KP) [138] & No & Operator \\
\hline Prandtl-Ishlinskii (PI) [138] & No & Operator \\
\hline Kuhnen [141] & Yes & Operator \\
\hline Bouc-Wen [142] & No & Differential \\
\hline Power-Law [143], Duhem [144] & Yes & Differential \\
\hline
\end{tabular}

approach that models hysteresis with a so-called hysteresis operator [140], [138], [141]. A simple form of such operators can be thought of a two-position relay, as the one found in the Preisach model [140]. Another common method uses a differential equation as means to describe hysteresis [142], [143], [144].

All of these models use a similar working principle: a set of experimental measurements is obtained on which the model parameters are fitted in an identification procedure [138]. Most often, the models are designed such that they capture the behavior of a given system (e.g. PEA), the nonlinear response can then be compensated with the use of the inverse of the model [141], [145], [146]. Alternatively, the model can also directly be fitted to the inverted data, as was shown in [139].

\section{EXAMPLES OF 3D PRINTED SENSORS}

This section shows some examples of 3D printed sensors that may be useful in electro and biomechanical applications.

\section{A. Piezoresistive sensors}

Traxel based 3D printed sensors using piezoresistive materials have a high sensitivity to strain and are therefore ideal for use in force and tactile sensing applications [4]. These sensors have been fabricated using co-printing with conductive pastes such as the bending sensor demonstrated by Nassar et al. [17] that uses silver palladium paste as the functional material. Gue et al. [90] demonstrated a small tactile sensor that is capable of sensing a person's pulse using a custom-made ink by using a mixture of silver particles and silicone elastomer. More practical applications of strain sensors can be found on sensing structures that use conductive polymer composites as functional material, such as tactile and touch sensors printed using soft conductive and nonconductive thermoplastic polyurethane (TPU) materials [112], [10]. These TPU materials allow for high flexibility, as shown in a proof of concept glove for measuring finger flexion by Christ et al. [147]. Kim et al. [86] demonstrated a multi-axial force sensor consisting of a 3D cross that allows for sensing forces in $x, y$ and $z$ direction using the same type of materials.

\section{B. Capacitive sensors}

In comparison to piezoresistive sensing methods, the capacitive sensing method has the advantage that the drift, nonlinearity and hysteresis in the conductive elements do not influence the measurement. The ability to $3 \mathrm{D}$ print very soft materials allows the fabrication of force sensors that consist of a parallel plate capacitor with a dielectric that is directly compressed [32], [148], [130], [149]. It should be noted that capacitive sensors often need shielding or guarding in order to reduce the influence of parasitic capacitances. Another commonly used technique is to print a conductive structure that forms a capacitive structure, which can detect changes in the dielectric constant of the materials in its environment. E.g., the capacitance will be changed by the presence of a finger, wood, glass or steel [150], [130].

\section{Inductive sensors}

The limited conductivity of carbon-based filaments is generally not sufficient for serving as inductors [66], [151]. 3D printed inductors can e.g. be fabricated by means of directly printing with Electrifi filament (see Table III] [66] or electroplating onto Electrifi material [119]. Other inductive coils and sensors are printed by means of embedding copper and nickel wire [31], by filling a 3D print with silver paste [152] or liquid metal [153], [154] or by spraying a graphene-filament coil with silver nano ink [151].

Because of the large piezoresistive constant of many of the conductors used in $3 \mathrm{D}$ printing, a piezoresistive sensor often is the easiest to implement solution. However, most piezoresistive materials show a large nonlinearity, and therefore a capacitive sensor might be useful in applications where a high linearity is desired, compensation is not feasible and shielding 
from parasitic capacitances is an option. When the used printing technology supports the fabrication of conductors with a high conductivity, inductive sensing methods can become another sensor that can be 3D printed.

\section{APPLICATIONS OF 3D PRINTED SENSORS}

\section{A. Biomedical}

3D printing technology enables the creation of low-cost and highly personalized structures [158]. Furthermore, the availability of soft and flexible materials make 3D printing an ideal technology for biomedical applications [147], [86], [112], [10], [113], [124] (see Table VIII). These soft materials easily follow complex body contours and have proven to be a useful alternative to gold standard electrodes for the use as biopotential electrodes to capture electroencephalography (EEG) [155] and electromyography (EMG) [10] signals. This opens the opportunity to create personalized electrode grids that could, for example, be co-printed with a prosthetic socket. Other applications are found in the development of finger strain sensor gloves to measures finger bending [147], tactile and pulse sensing [90] and minimal obtrusive fingertip shearforce sensors [113] as shown in Figure 6a.

\section{B. Soft Robotics}

The current advancements in 3D printing and functional materials enable the development of 3D printed soft sensors. By means of multi-material embedded 3D printing, sensors with customized geometry and functionality can be embedded in soft robots together with soft actuators, where integration is a key component for closed-loop control [159]. A big advantage of multi-material FDM in this respect is that a single fabrication process can fabricate soft robots with integrated sensors, actuators, control and power delivery [160]. The required limited dimension and spatial distribution are still challenges for current 3D printing technology. Among others, FDM still has limitations in terms of resolution, speed and material compatibility and can only use thermoplastics, which may not be resilient and stretchable enough [160]. If the printing resolution can be increased, a higher density of sensors and actuators becomes possible, enabling improved soft robots.

Current research mainly focuses on single sensors, where piezoresistive and capacitive sensors are used mostly for strain measurements [161], [160]. However, so far integrated 3D printed sensors with actuators for soft robotics are limited in literature [159]. The bulk of the work with traxel-based printing focuses on integrated piezoresistive strain sensors in 3D printed pneumatic actuators [124], [127], [162], [156] (see Table VIII. For pneumatic actuators either the full actuator can be made out of piezoresistive material [124] (fig 6, or strain gauges can be embedded by means of printing [127], [163] (fig 6] or including conductors e.g. silver paste [162]. Other work presents the use of conductive TPU as a combined heater and piezoresistive angle sensor in a variable stiffness gripper [157]. 3D printing provides new opportunities for developing autonomous soft robots, however, research on this topic has only just started. (a)

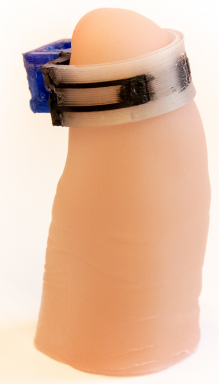

(b)

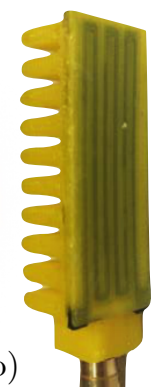

Fig. 6. (a) 3D Printed fingertip shear and normal force sensor [113 (C)[2019] IEEE). (b) Pneumatic actuator with integrated strain sensor for angle measurements 156

\section{CONCLUSION}

This work has described the different techniques that can be used to extrude filaments, inks and fibers. The extrusion of flexible filaments is ideally done using a direct-drive, despite a Bowden extruder offers a lower mass. Fiber placement and coextrusion both appear to be well suited for the fabrication of 3D printed sensors, however, printing anything else than prepreg carbon fibers and printing fibers outside of the $x-y$ plane appears still to be challenging. The extrusion of relatively low-cost and viscous inks is best done using a progressive cavity extruder, while for more expensive or less viscous inks, respectively, a pneumatic or syringe extruder might be better suited.

Furthermore, this work has provided a list of techniques that are in use to overcome the challenges of switching between different materials. It also listed some of the work done on overcoming some of the challenges of 3D printed sensors, such as how to characterize the anisotropic conduction of the 3D printed conductors, how to connect the sensors to the readout electronics, how to reduce the drift of the sensors and how to model and subsequently compensate for nonlinear behavior.

It was shown that $3 \mathrm{D}$ printing is already being used to print a wide range of electro- and biomechanical sensors where piezoresistive sensors offer a simple and cheap way to integrate sensing, whereas capacitive sensors offer a way to create more linear sensors in exchange for added complexity.

\section{$X$. Discussion And Future outlook}

Recently techniques have become available that allow switching between different types of extruders. Once the mutual alignment-precision of the different tool-heads has been sufficiently taken care of, it can be expected that there will be an increase in the number of systems that combine multiple extrusion techniques.

When the ability of 3D printers to deposit an increasing variety of materials, and with better resolutions, is realised the complexity of sensor systems that can be printed eventually will become comparable to those of integrated circuits or even to nature. Once sensor systems of this degree of complexity are combined with actuators of similar complexity and paired with artificial intelligence, such systems might eventually get closer to nature's capabilities of sensing and manipulating in real world applications. 
TABLE VIII

OVERVIEW APPLICATION AND FABRICATION OF 3D PRINTED SENSORS

\begin{tabular}{|c|c|c|c|c|c|c|c|}
\hline Reference & Application & $\begin{array}{l}\text { Sensor } \\
\text { type }\end{array}$ & $\begin{array}{l}\text { Transduction } \\
\text { method }\end{array}$ & $\begin{array}{l}\text { Extrusion } \\
\text { method }\end{array}$ & $\begin{array}{l}\text { Toolswitching } \\
\text { system }\end{array}$ & $\begin{array}{l}\text { Conductive } \\
\text { material }\end{array}$ & $\begin{array}{l}\text { Sensing } \\
\text { material }\end{array}$ \\
\hline$[113$ & Biomedical & Shear & Piezoresistive & FDM & Rotary multi-toolhead & N.A. & PI-ETPU 85-700+ \\
\hline 147 & Biomedical & Bending angle & Piezoresistive & FDM & Stationary nozzles & N.A. & $\mathrm{TPU}+3 \% \mathrm{MWCNT}$ \\
\hline [112] & Biomedical & Force & Piezoresistive & FDM & Stationary nozzles & N.A. & PI-ETPU 95-250 \\
\hline 54 & Biomedical & EMG & Biopotential & FDM & Stationary nozzles & PI-ETPU 95-250 & N.A. \\
\hline 155 & Biomedical & EEG & Biopotential & FDM & N.A. & Silver Paint & N.A. \\
\hline 90$]$ & Biomedical & Pressure & Piezoresistive & Direct ink writing & Independent multi-toolhead & Silicone $+75 \% \mathrm{Ag}$ & Silicone $+68 \% \mathrm{Ag}$ \\
\hline [124] & Soft Robotics & Bending angle & Piezoresistive & FDM & Single nozzle & N.A. & TPU $+1 \%$ MWCNT \\
\hline 127 & Soft Robotics & Bending angle & Piezoresistive & FDM & Single nozzle & N.A. & $\mathrm{TPU}+11 \% \mathrm{MWCNT}$ \\
\hline 156 & Soft Robotics & Bending angle & Piezoresistive & FDM & Stationary nozzles & N.A. & Protopasta Conductive PLA \\
\hline 157 & Soft Robotics & Bending angle & Piezoresistive & FDM & Stationary nozzles & N.A. & PI-ETPU 95-250 \\
\hline
\end{tabular}

\section{REFERENCES}

[1] C. Weller, R. Kleer, and F. T. Piller, "Economic implications of 3D printing: Market structure models in light of additive manufacturing revisited," International Journal of Production Economics, vol. 164, pp. 43-56, 2015. [Online]. Available: http://dx.doi.org/10.1016/ j.ijpe.2015.02.020

[2] T. Pereira, J. V. Kennedy, and J. Potgieter, "A comparison of traditional manufacturing vs additive manufacturing, the best method for the job," Procedia Manufacturing, vol. 30, pp. 11-18, 2019. [Online]. Available: https://doi.org/10.1016/j.promfg.2019.02.003

[3] M. Attaran, "The rise of 3-D printing: The advantages of additive manufacturing over traditional manufacturing," Business Horizons, vol. 60, no. 5, pp. 677-688, 2017. [Online]. Available: http://dx.doi.org/10.1016/j.bushor.2017.05.011

[4] Y. Xu, X. Wu, X. Guo, B. Kong, M. Zhang, X. Qian, S. Mi, and W. Sun, "The Boom in 3D-Printed Sensor Technology," Sensors (Basel, Switzerland), vol. 17, no. 5, pp. 1-37, 2017.

[5] M. R. Khosravani and T. Reinicke, "3D-printed sensors: Current progress and future challenges," Sensors and Actuators, A: Physical, vol. 305, p. 111916, 2020. [Online]. Available: https://doi.org/10.1016/ j.sna.2020.111916

[6] A. Dijkshoorn, P. Werkman, M. Welleweerd, G. Wolterink, B. Eijking, J. Delamare, R. Sanders, and G. J. Krijnen, "Embedded sensing: Integrating sensors in 3-D printed structures," Journal of Sensors and Sensor Systems, vol. 7, no. 1, pp. 169-181, 2018.

[7] A. Dijkshoorn, M. Schouten, G. Wolterink, R. Sanders, S. Stramigioli, and G. Krijnen, "Characterizing the Electrical Properties of Anisotropic, 3D-Printed Conductive Sheets for Sensor Applications," IEEE Sensors Journal, 2020.

[8] O. Stř́teský, J. Průša, and M. Bach, Basics of $3 D$ Printing with Josef Prusa. Prusa Research s.r.o., 2019. [Online]. Available: https: //www.prusa3d.com/ebook-basics-of-3d-printing-with-josef-prusa/

[9] B. Redwoon, F. Schöffer, and B. Garret, The 3D printing handbook. Coers \& Roest, 2017.

[10] G. Wolterink, R. Sanders, F. Muijzer, B. J. Van Beijnum, and G. Krijnen, "3D-printing soft sEMG sensing structures," Proceedings of IEEE Sensors, vol. 2017-Decem, pp. 1-3, 2017.

[11] Capricorn Premium Bowden Tubing, "Capricorn Premium PTFE Bowden Tubing." [Online]. Available: https://www.captubes.com/

[12] M. A. Skylar-Scott, S. Gunasekaran, and J. A. Lewis, "Laser-assisted direct ink writing of planar and 3D metal architectures," Proceedings of the National Academy of Sciences of the United States of America, vol. 113 , no. 22 , pp. $6137-6142,2016$.

[13] C. F. Revelo and H. A. Colorado, "3D printing of kaolinite clay ceramics using the Direct Ink Writing (DIW) technique," Ceramics International, vol. 44, no. 5, pp. 5673-5682, 2018. [Online]. Available: http://dx.doi.org/10.1016/j.ceramint.2017.12.219

[14] M. Rosenthal, C. Henneberger, A. Gutkes, and C. T. Bues, "Liquid Deposition Modeling: a promising approach for 3D printing of wood," European Journal of Wood and Wood Products, vol. 76, no. 2, pp. 797-799, 2018.

[15] M. A. Skylar-Scott, J. Mueller, C. W. Visser, and J. A. Lewis, "Voxelated soft matter via multimaterial multinozzle 3D printing," Nature, vol. 575, no. 7782 , pp. 330-335, 2019. [Online]. Available: http://dx.doi.org/10.1038/s41586-019-1736-8

[16] H. Yuk and X. Zhao, "A New 3D Printing Strategy by Harnessing Deformation, Instability, and Fracture of Viscoelastic Inks," Advanced Materials, vol. 30, no. 6, pp. 1-8, 2018.

[17] H. Nassar, M. Ntagios, W. T. Navaraj, and R. Dahiya, "Multi-Material 3D Printed Bendable Smart Sensing Structures," Proceedings of IEEE Sensors, vol. 2018-Octob, pp. 3-6, 2018.
[18] J. W. Boley, E. L. White, G. T. Chiu, and R. K. Kramer, "Direct writing of gallium-indium alloy for stretchable electronics," Advanced Functional Materials, vol. 24, no. 23, pp. 3501-3507, 2014.

[19] R. Clift, J. Grace, and M. Weber, Bubbles, Drops and Particles. New York: Academic Press, Inc., 1978.

[20] F. Tricot, C. Venet, D. Beneventi, D. Curtil, D. Chaussy, T. P. Vuong, J. E. Broquin, and N. Reverdy-Bruas, "Fabrication of 3D conductive circuits: Print quality evaluation of a direct ink writing process," RSC Advances, vol. 8, no. 46, pp. 26036-26046, 2018.

[21] G. Wang, L. Yao, W. Wang, J. Ou, C. Y. Cheng, and H. Ishii, "XPrint: A modularized liquid printer for smart materials deposition," Conference on Human Factors in Computing Systems - Proceedings, pp. 5743-5752, 2016. [Online]. Available: http://dx.doi.org/10.1145/ 2858036.2858281

[22] "ViscoTec Pumpen- u. Dosiertechnik GmbH", private communication, 2020.

[23] G. V. Bobashev and W. A. Zule, "Modeling the effect of high deadspace syringes on the human immunodeficiency virus (HIV) epidemic among injecting drug users," Addiction, vol. 105, no. 8, pp. 1439-1447, 2010.

[24] S. M. Kabir, K. Mathur, and A. F. M. Seyam, "A critical review on 3D printed continuous fiber-reinforced composites: History, mechanism, materials and properties," Composite Structures, vol. 232, no. August 2019, pp. 1-24, 2020.

[25] X. Yao, C. Luan, D. Zhang, L. Lan, and J. Fu, "Evaluation of carbon fiber-embedded 3D printed structures for strengthening and structuralhealth monitoring," Materials and Design, vol. 114, pp. 424-432, 2017. [Online]. Available: http://dx.doi.org/10.1016/j.matdes.2016.10.078

[26] S. Swaminathan, K. B. Ozutemiz, C. Majidi, and S. E. Hudson, "FiberWire: Embedding Electronic Function into 3D Printed Mechanically Strong, Lightweight Carbon Fiber Composite Objects," Proceedings of the 2019 CHI Conference on Human Factors in Computing Systems - CHI '19, no. Figure 1, pp. 1-11, 2019. [Online]. Available: http://dl.acm.org/citation.cfm?doid=3290605.3300797

[27] C. Shemelya, L. Banuelos-Chacon, A. Melendez, C. Kief, D. Espalin, R. Wicker, G. Krijnen, and E. Macdonald, "Multi-functional 3D printed and embedded sensors for satellite qualification structures," 2015 IEEE SENSORS - Proceedings, pp. 1422-1425, 2015.

[28] Z. Wang, C. Luan, G. Liao, X. Yao, and J. Fu, "Mechanical and self-monitoring behaviors of 3D printing smart continuous carbon fiber-thermoplastic lattice truss sandwich structure," Composites Part B: Engineering, vol. 176, no. April, p. 107215, 2019. [Online]. Available: https://doi.org/10.1016/j.compositesb.2019.107215

[29] C. Luan, X. Yao, C. Liu, L. Lan, and J. Fu, "Self-monitoring continuous carbon fiber reinforced thermoplastic based on dualmaterial three-dimensional printing integration process," Carbon, vol. 140, pp. 100-111, 2018. [Online]. Available: https://doi.org/10.1016/ j.carbon.2018.08.019

[30] Brightlands Materials Center, "Brightlands Materials Center Develops Self-Sensing in 3D Printed Fiber Reinforced Thermoplastics." [Online]. Available: https://www.brightlandsmaterialscenter.com/selfsensing-in-3d-printed-thermoplastic-composites/

[31] M. Saari, B. Cox, E. Richer, P. S. Krueger, and A. L. Cohen, "Fiber encapsulation additive manufacturing: An enabling technology for 3D printing of electromechanical devices and robotic components," $3 D$ Printing and Additive Manufacturing, vol. 2, no. 1, pp. 32-39, 2015.

[32] M. Saari, B. Xia, B. Cox, P. S. Krueger, A. L. Cohen, and E. Richer, "Fabrication and Analysis of a Composite 3D Printed Capacitive Force Sensor," 3D Printing and Additive Manufacturing, vol. 3, no. 3, pp. 137-141, 2016. 
[33] C. Shemelya, F. Cedillos, E. Aguilera, D. Espalin, D. Muse, R. Wicker, and E. Macdonald, "Encapsulated copper wire and copper mesh capacitive sensing for 3-D printing applications," IEEE Sensors Journal, vol. 15, no. 2, pp. 1280-1286, 2015.

[34] E. Aguilera, J. Ramos, D. Espalin, F. Cedillos, D. Muse, R. Wicker, and E. MacDonald, "3D printing of electro mechanical systems," 24 th International SFF Symposium - An Additive Manufacturing Conference, SFF 2013, no. January, pp. 950-961, 2013

[35] D. Espalin, D. W. Muse, E. MacDonald, and R. B. Wicker, "3D Printing multifunctionality: Structures with electronics," International Journal of Advanced Manufacturing Technology, vol. 72, no. 5-8, pp. 963-978, 2014

[36] L. G. Blok, M. L. Longana, H. Yu, and B. K. Woods, "An investigation into 3D printing of fibre reinforced thermoplastic composites," Additive Manufacturing, vol. 22, no. April, pp. 176-186, 2018.

[37] D. Pascale and I. Simion, "Multi-Material 3D Printer Extruder Concept," Journal of Industrial Design and Engineering Graphics, vol. 13, no. 1, pp. 25-28, 2018.

[38] Prusa Research, "Original Prusa Multi Material 2S," 2020. [Online]. Available: https://www.prusa3d.com/original-prusa-i3-multi-material$2-0 /$

[39] Mosaic Manufacturing Ltd, "Simple, multi-material 3D printing." [Online]. Available: https://www.mosaicmfg.com/

[40] E3D-Online Ltd, "Cyclops." [Online]. Available: https://e3donline.dozuki.com/c/Cyclops

[41] RepRap ApS, "Diamond Hotend." [Online]. Available: https:// www.reprap.me/extruder/diamond-hotend

[42] Makerbot, "MakerBot Replicator 2X Video Tutorials." [Online]. Available: https://www.makerbot.com/stories/news/makerbot-replicator-2xvideo-tutorials/

[43] Ord solutions, "RoVa3D - A 3D Printer Based on FDM and FFF Technology," 2020. [Online]. Available: https://www.ordsolutions.com/ rova-3d-fdm-printer

[44] Ultimaker BV, "Ultimaker S3 and Ultimaker S5." [Online]. Available: https://support.ultimaker.com/hc/en-us/article_attachments/ 360010642079/User-manual-Ultimaker-S3-S5-v2.4.pdf

[45] Makerbot, "Method." [Online]. Available: https://www.makerbot.com/ 3d-printers/method/

[46] Electronic Alchemy, "eForge 3D Printer." [Online]. Available: https://www.electronicalchemy.com/eforge/

[47] Leapfrog 3D Printers, "Bolt pro." [Online]. Available: https: //www.lpfrg.com/products/leapfrog-bolt-pro/

[48] BNC3D, "Helping innovators create the future." [Online]. Available: https://www.ben3d.com/

[49] Titan Robotics Ltd, "The Cronus." [Online]. Available: https: //titan3drobotics.com/the-cronus/

[50] Diabase Engineering, "A MACHINE SHOP ON A BENCHTOP," 2020. [Online]. Available: https://www.diabasemachines.com

[51] A. R. Avdeev, A. A. Shvets, and I. S. Torubarov, "Investigation of Kinematics of 3D Printer Print Head Moving Systems," in Lecture Notes in Mechanical Engineering. Springer, 2020, pp. 461-471.

[52] E3D-Online Ltd, "ToolChanger." [Online]. Available: https: //github.com/e3donline/ToolChanger

[53] Anisoprint Sarl, "CCF\&CBF." [Online]. Available: https: //anisoprint.com/product-cf

[54] G. Wolterink, P. Dias, R. G. Sanders, F. Muijzer, B. J. van Beijnum, P. Veltink, and G. Krijnen, "Development of soft semg sensing structures using 3d-printing technologies," Sensors (Switzerland), vol. 20, no. 15, pp. 1-19, 2020.

[55] ProtoPlant, makers of Proto-pasta, "Composite PLA - Electrically Conductive Graphite." [Online]. Available: https://www.proto-pasta.com/

[56] Proto-pasta, "CPD1xxxx Safety Data Sheet," https://cdn.shopify.com/ s/files/1/0717/9095/files/CDP1xxxx_SDS.pdf

[57] Graphene 3D Lab, "Conductive Graphene PLA Filament." [Online] Available: http://www.blackmagic3d.com/Conductive-p/grphn-pla.htm

[58] Graphene 3D Lab Inc., "Material Safety Data Sheet." [Online]. Available: http://graphenelab.com/pdf/conductivemsds.pdf

[59] Multi3D, "Electrifi Conductive Filament." [Online]. Available: https: //www.multi3dllc.com/product/electrifi/

[60] Palmiga Innovation, "PI-ETPU 95-250 Carbon Black." [Online]. Available: https://rubber3dprinting.com/pi-etpu-95-250-carbon-black/

[61] Ninjatek, "Eel 3D Printing Filament." [Online]. Available: http: //ninjatek.com/wp-content/uploads/2018/12/Eel-TDS.pdf

[62] — "Safety Data Sheet." [Online]. Available: http://ninjatek.com/ wp-content/uploads/2018/12/SDS_EEL.pdf
[63] G. Wolterink, R. Sanders, and G. Krijnen, "Thin, Flexible, Capacitive Force Sensors Based on Anisotropy in 3D-Printed Structures," Proceedings of IEEE Sensors, vol. 2018-Octob, pp. 2-5, 2018.

[64] J. F. Christ, N. Aliheidari, A. Ameli, and P. Pötschke, "3D printed highly elastic strain sensors of multiwalled carbon nanotube/thermoplastic polyurethane nanocomposites," Materials and Design, vol. 131, pp. 394-401, 2017.

[65] S. W. Kwok, K. H. H. Goh, Z. D. Tan, S. T. M. Tan, W. W. Tjiu, J. Y. Soh, Z. J. G. Ng, Y. Z. Chan, H. K. Hui, and K. E. J. Goh, "Electrically conductive filament for 3D-printed circuits and sensors," Applied Materials Today, vol. 9, pp. 167-175, 2017. [Online] Available: http://dx.doi.org/10.1016/j.apmt.2017.07.001

[66] P. F. Flowers, C. Reyes, S. Ye, M. J. Kim, and B. J. Wiley, "3D printing electronic components and circuits with conductive thermoplastic filament," pp. 156-163, 2017.

[67] S. F. Acquah, B. E. Leonhardt, M. S. Nowotarski, J. M. Magi, K. A. Chambliss, T. E. Venzel, S. D. Delekar, and L. A. Al-Hariri, "Carbon Nanotubes and Graphene as Additives in 3D Printing," Carbon Nanotubes - Current Progress of their Polymer Composites, 2016.

[68] L. Flandin, A. Hiltner, and E. Baer, "Interrelationships between electrical and mechanical properties of a carbon black-filled ethylene-octene elastomer," Polymer, vol. 42, no. 2, pp. 827-838, 2001.

[69] F. Gubbels, S. Blacher, E. Vanlathem, R. Jérôme, R. Deltour, F. Brouers, and P. Teyssié, "Design of Electrical Conductive Composites: Key Role of the Morphology on the Electrical Properties of Carbon Black Filled Polymer Blends," Macromolecules, vol. 28, no. 5, pp. 1559-1566, 1995.

[70] S. H. Munson-Mcgee, "Estimation of the critical concentration in an anisotropic percolation network," Physical Review B, vol. 43, no. 4 , pp. 3331-3336, 1991.

[71] A. D. Valentine, T. A. Busbee, J. W. Boley, J. R. Raney, A. Chortos, A. Kotikian, J. D. Berrigan, M. F. Durstock, and J. A. Lewis, "Hybrid 3D Printing of Soft Electronics," Advanced Materials, vol. 29, no. 40, pp. $1-8,2017$.

[72] H. Kipphan, Handbook of Print Media. Springer-Verlag Berlin Heidelberg, 2001, vol. 13, no. 6.

[73] Z. Zhu, H. Wang, and D. Peng, "Dependence of sediment suspension viscosity on solid concentration: A simple general equation," Water (Switzerland), vol. 9, no. 7, 2017.

[74] H. Yuk, B. Lu, S. Lin, K. Qu, J. Xu, J. Luo, and X. Zhao, "3D printing of conducting polymers," Nature Communications, vol. 11, no. 1, pp. 4-11, 2020. [Online]. Available: http://dx.doi.org/10.1038/ s41467-020-15316-7

[75] D. N. Heo, S. J. Lee, R. Timsina, X. Qiu, N. J. Castro, and L. G. Zhang, "Development of 3D printable conductive hydrogel with crystallized PEDOT:PSS for neural tissue engineering," Materials Science and Engineering C, vol. 99, no. September 2018, pp. 582-590, 2019. [Online]. Available: https://doi.org/10.1016/j.msec.2019.02.008

[76] Engineered Conductive Materials LLC, "Technical Data Sheet CI-1036." [Online]. Available: http://www.conductives.com/pdfs/CI1036.pdf

[77] J. Suikkola, T. Kankkunen, P. Iso-Ketola, J. Vanhala, and M. Mantysalo, "Screen-Printed Stretchable Interconnects," Proceedings - Electronic Components and Technology Conference, vol. 2016-Augus, pp. 16501655, 2016.

[78] Henkel Corporation, "LOCTITE EDAG PD004A E\&C," https://www.henkel-adhesives.com/nl/en/product/inks-_-coatings/ loctite_edag_pd_004aec.html

[79] Electrolube, "Technical Data Sheet." [Online]. Available: https: //electrolube.com/wp-content/uploads/2019/11/SCP_lhptji.pdf

[80] Dupont, "DUPONT ${ }^{\overline{1 N 1}}$ PE410." [Online]. Available: https://www.dupont.com/content/dam/dupont/amer/us/en/products/ ei-transformation/documents/PE410-Data-Sheet.pdf

[81] F. Antonov, "CONTINUOUS FIBER 3D PRINTING: CURRENT MARKET REVIEW BY FEDOR ANTONOV, CEO ANISOPRINT," 2019. [Online]. Available: https://3dprintingindustry.com/news/continuous-fiber-3d-printingcurrent-market-review-by-fedor-antonov-ceo-anisoprint-164964/

[82] C. Votzke, U. Daalkhaijav, Y. Menguc, and M. L. Johnston, "3D-Printed Liquid Metal Interconnects for Stretchable Electronics," IEEE Sensors Journal, vol. 19, no. 10, pp. 3832-3840, 2019.

[83] H. Ota, S. Emaminejad, Y. Gao, A. Zhao, E. Wu, S. Challa, K. Chen, H. M. Fahad, A. K. Jha, D. Kiriya, W. Gao, H. Shiraki, K. Morioka, A. R. Ferguson, K. E. Healy, R. W. Davis, and A. Javey, "Application of 3D Printing for Smart Objects with Embedded Electronic Sensors and Systems," Advanced Materials Technologies, vol. 1, no. 1, pp. 1-8, 2016. 
[84] S. Liu, K. Sweatman, S. McDonald, and K. Nogita, "Ga-based alloys in microelectronic interconnects: A review," Materials, vol. 11, no. 8, pp. 1-20, 2018.

[85] Y. Cui, Y. Ding, S. Xu, Z. Yang, P. Zhang, W. Rao, and J. Liu, "Liquid Metal Corrosion Effects on Conventional Metallic Alloys Exposed to Eutectic Gallium-Indium Alloy Under Various Temperature States," International Journal of Thermophysics, vol. 39, no. 10, pp. 1-14, 2018. [Online]. Available: https://doi.org/10.1007/s10765-018-2440-x

[86] K. Kim, J. Park, J. h. Suh, M. Kim, Y. Jeong, and I. Park, "3D printing of multiaxial force sensors using carbon nanotube (CNT)/thermoplastic polyurethane (TPU) filaments," Sensors and Actuators, A: Physical, vol. 263, pp. 493-500, 2017. [Online]. Available: http://dx.doi.org/10.1016/j.sna.2017.07.020

[87] N. C. Das, T. K. Chaki, and D. Khastgir, "Effect of axial stretching on electrical resistivity of short carbon fibre and carbon black filled conductive rubber composites," Polymer International, vol. 51, no. 2, pp. 156-163, 2002.

[88] K. P. Sau, T. K. Chaki, and D. Khastgir, "The effect of compressive strain and stress on electrical conductivity of conductive rubber composites," Rubber Chemistry and Technology, vol. 73, no. 2, pp. 310$324,2000$.

[89] H. J. Qi and M. C. Boyce, "Stress-strain behavior of thermoplastic polyurethanes," Mechanics of Materials, vol. 37, no. 8, pp. 817-839, 2005.

[90] S. Z. Guo, K. Qiu, F. Meng, S. H. Park, and M. C. McAlpine, "3D Printed Stretchable Tactile Sensors," Advanced Materials, vol. 29, no. 27, pp. 1-8, 2017.

[91] U. Daalkhaijav, O. D. Yirmibesoglu, S. Walker, and Y. Mengüç, "Rheological Modification of Liquid Metal for Additive Manufacturing of Stretchable Electronics," Advanced Materials Technologies, vol. 3, no. 4, pp. 1-9, 2018.

[92] Y. L. Park, B. R. Chen, and R. J. Wood, "Design and fabrication of soft artificial skin using embedded microchannels and liquid conductors," IEEE Sensors Journal, vol. 12, no. 8, pp. 2711-2718, 2012.

[93] H. Kim, F. Torres, Y. Wu, D. Villagran, Y. Lin, and T.-L. Tseng, "Integrated 3D printing and corona poling process of PVDF piezoelectric films for pressure sensor application," Smart Materials and Structures, vol. 26, no. 8, p. 085027, 2017.

[94] H. Kim, F. Torres, D. Villagran, C. Stewart, Y. Lin, and T. L. B Tseng, "3D Printing of BaTiO3/PVDF Composites with Electric In Situ Poling for Pressure Sensor Applications," Macromolecular Materials and Engineering, vol. 302, no. 11, pp. 1-6, 2017.

[95] S. Rajala, M. Schouten, G. Krijnen, and S. Tuukkanen, "High BendingMode Sensitivity of Printed Piezoelectric Poly(vinylidenefluoride- cotrifluoroethylene) Sensors," ACS Omega, vol. 3, no. 7, pp. 8067-8073, 2018.

[96] S. Bodkhe, P. S. Rajesh, F. P. Gosselin, and D. Therriault, "Simultaneous 3D Printing and Poling of PVDF and Its Nanocomposites," ACS Applied Energy Materials, vol. 1, no. 6, pp. 2474-2482, 2018.

[97] E. R. Cholleti, "A Review on 3D printing of piezoelectric materials," IOP Conference Series: Materials Science and Engineering, vol. 455, no. $1,2018$.

[98] C. Lee and J. A. Tarbutton, "Electric Poling-assisted Additive Manufacturing Process for Lead-free Piezoelectric Device Fabrication," Procedia Manufacturing, vol. 1, pp. 320-326, 2015. [Online]. Available: http://dx.doi.org/10.1016/j.promfg.2015.09.035

[99] I. Kierzewski, S. S. Bedair, B. Hanrahan, H. Tsang, L. Hu, and N. Lazarus, "Adding an electroactive response to 3D printed materials: Printing a piezoelectret," Additive Manufacturing, vol. 31, no. July 2019, p. 100963, 2020. [Online]. Available: https: //doi.org/10.1016/j.addma.2019.100963

[100] Proto-pasta, "Iron-filled Metal Composite PLA." [Online]. Available: https://www.proto-pasta.com/products/magnetic-iron-pla

[101] Magnetfabric bonn, "Neofer 25/60p." [Online]. Available: https://magnetfabrik.de/wp-content/uploads/produkte/materiallist-according-to-din/refeb/neofer-25-60p.pdf

[102] C. Huber, C. Abert, F. Bruckner, M. Groenefeld, O. Muthsam, S. Schuschnigg, K. Sirak, R. Thanhoffer, I. Teliban, C. Vogler, R. Windl, and D. Suess, "3D print of polymer bonded rare-earth magnets, and 3D magnetic field scanning with an end-user 3D printer," Applied Physics Letters, vol. 109, no. 16, 2016. [Online]. Available: http://dx.doi.org/10.1063/1.4964856

[103] Z. Wang, C. Huber, J. Hu, J. He, D. Suess, and S. X. Wang, "An electrodynamic energy harvester with a 3D printed magnet and optimized topology," Applied Physics Letters, vol. 114, no. 1, 2019. [Online]. Available: http://dx.doi.org/10.1063/1.5074123
[104] R. Wagner, L. Brandl, W. Kersten, S. Sponar, Y. Hasegawa, C. Huber, F. Bruckner, and D. Suess, "3D printed magnets for neutron spin manipulation," EPJ Web of Conferences, vol. 219, p. 10008, 2019.

[105] K. von Petersdorff-Campen, Y. Hauswirth, J. Carpenter, A. Hagmann, S. Boës, M. S. Daners, D. Penner, and M. Meboldt, "3D printing of functional assemblies with integrated polymer-bonded magnets demonstrated with a prototype of a rotary blood pump," Applied Sciences (Switzerland), vol. 8, no. 8, 2018.

[106] L. Li, A. Tirado, I. C. Nlebedim, O. Rios, B. Post, V. Kunc, R. R. Lowden, E. Lara-Curzio, R. Fredette, J. Ormerod, T. A. Lograsso, and M. P. Paranthaman, "Big Area Additive Manufacturing of High Performance Bonded NdFeB Magnets," Scientific Reports, vol. 6, no. October, pp. 1-7, 2016.

[107] S. J. Leigh, C. P. Purssell, D. R. Billson, and D. A. Hutchins, "Using a magnetite/thermoplastic composite in 3D printing of direct replacements for commercially available flow sensors," Smart Materials and Structures, vol. 23, no. 9, 2014.

[108] H. Watschke, K. Hilbig, and T. Vietor, "Design and characterization of electrically conductive structures additively manufactured by material extrusion," Applied Sciences (Switzerland), vol. 9, no. 4, pp. 1-25, 2019.

[109] S. J. Leigh, R. J. Bradley, C. P. Purssell, D. R. Billson, and D. A. Hutchins, "A Simple, Low-Cost Conductive Composite Material for 3D Printing of Electronic Sensors," PLoS ONE, vol. 7, no. 11, pp. $1-6,2012$

[110] W. Lang, F. Jakobs, E. Tolstosheeva, H. Sturm, A. Ibragimov, A. Kesel, D. Lehmhus, and U. Dicke, "From embedded sensors to sensorial materials - The road to function scale integration," Sensors and Actuators, A: Physical, vol. 171, no. 1, pp. 3-11, 2011. [Online] Available: http://dx.doi.org/10.1016/j.sna.2011.03.061

[111] M. Maurizi, J. Slavič, F. Cianetti, M. Jerman, J. Valentinčič, A. Lebar, and M. Boltežar, "Dynamic measurements using FDM 3D-printed embedded strain sensors," Sensors (Switzerland), vol. 19, no. 12, pp. $1-15,2019$.

[112] B. Eijking, R. Sanders, and G. Krijnen, "Development of whisker inspired 3D multi-material printed flexible tactile sensors," Proceedings of IEEE Sensors, vol. 2017-Decem, pp. 1-3, 2017.

[113] G. Wolterink, R. Sanders, and G. Krijnen, "A flexible, three material, 3D-printed, shear force sensor for use on finger tips," Proceedings of IEEE Sensors, vol. 2019-Octob, pp. 2-5, 2019.

[114] A. Dijkshoorn, P. Neuvel, S. Stramigioli, and G. Krijnen, "In-Situ Monitoring of Layer-Wise Fabrication by Electrical Resistance Measurements in 3D Printing," Proceedings of IEEE Sensors, 2020, to be published.

[115] J. R. McGhee, M. Sinclair, D. J. Southee, and K. G. Wijayantha, "Strain sensing characteristics of 3D-printed conductive plastics," Electronics Letters, vol. 54, no. 9, pp. 570-572, 2018.

[116] Z. Abass, W. Meng, S. Q. Xie, and Z. Zhang, "A robust, practical upper limb electromyography interface using dry 3D printed electrodes," IEEE/ASME International Conference on Advanced Intelligent Mechatronics, AIM, vol. 2019-July, pp. 453-458, 2019.

[117] B. Hampel, S. Monshausen, and M. Schilling, "Properties and applications of electrically conductive thermoplastics for additive manufacturing of sensors," Technisches Messen, vol. 84, no. 9, pp. 593-599, 2017.

[118] P. Wiebe, P. Beierle, H. C. Shao, B. Gergely, A. F. Starace, and H. Batelaan, "Performance of plastic electron optics components fabricated using a 3D printer," Ultramicroscopy, vol. 205, pp. 70-74, 2019.

[119] M. J. Kim, M. A. Cruz, S. Ye, A. L. Gray, G. L. Smith, N. Lazarus, C. J. Walker, H. H. Sigmarsson, and B. J. Wiley, "One-step electrodeposition of copper on conductive 3D printed objects," Additive Manufacturing, vol. 27, no. November 2018, pp. 318-326, 2019. [Online]. Available: https://doi.org/10.1016/j.addma.2019.03.016

[120] S. H. Ahn, M. Montero, D. Odell, S. Roundy, and P. K. Wright, "Anisotropic material properties of fused deposition modeling ABS," Rapid Prototyping Journal, vol. 8, no. 4, pp. 248-257, 2002.

[121] H. Prajapati, D. Ravoori, R. L. Woods, and A. Jain, "Measurement of anisotropic thermal conductivity and inter-layer thermal contact resistance in polymer fused deposition modeling (FDM)," Additive Manufacturing, vol. 21, no. February, pp. 84-90, 2018. [Online]. Available: https://doi.org/10.1016/j.addma.2018.02.019

[122] M. V. Patton, P. Ryan, T. Calascione, N. Fischer, A. Morgenstern, N. Stenger, and B. B. Nelson-Cheeseman, "Manipulating magnetic anisotropy in fused filament fabricated parts via macroscopic shape, mesoscopic infill orientation, and infill percentage," Additive Manufacturing, vol. 27, no. November 2018, pp. 482-488, 2019. [Online]. Available: https://doi.org/10.1016/j.addma.2019.03.026 
[123] J. Zhang, B. Yang, F. Fu, F. You, X. Dong, and M. Dai, "Resistivity and Its Anisotropy Characterization of 3D-Printed Acrylonitrile Butadiene Styrene Copolymer (ABS)/Carbon Black (CB) Composites," Applied Sciences, vol. 7, no. 1, p. 20, 2017.

[124] C. J. Hohimer, G. Petrossian, A. Ameli, C. Mo, and P. Pötschke, "3D Printed Conductive Thermoplastic Polyurethane/Carbon Nanotube Composites for Capacitive and Piezoresistive Sensing in Soft Pneumatic Actuators," Additive Manufacturing, p. 101281, 2020.

[125] L. Truman, E. Whitwam, B. B. Nelson-Cheeseman, and L. J. Koerner, "Conductive 3D printing: resistivity dependence upon infill pattern and application to EMI shielding," Journal of Materials Science: Materials in Electronics, no. 0123456789, 2020. [Online]. Available: https://doi.org/10.1007/s10854-020-03965-9

[126] S. Lin, L. Xia, G. Ma, S. Zhou, and Y. M. Xie, "A maze-like path generation scheme for fused deposition modeling," International Journal of Advanced Manufacturing Technology, vol. 104, no. 1-4, pp. 1509-1519, 2019.

[127] S. Mousavi, D. Howard, F. Zhang, J. Leng, and C. H. Wang, "Direct 3D Printing of Highly Anisotropic, Flexible, Constriction-Resistive Sensors for Multidirectional Proprioception in Soft Robots," ACS Applied Materials \& Interfaces, vol. 12, no. 13, pp. 15631-15643, 2020.

[128] P. P. L. Regtien, F. van der Heijden, M. J. Korsten, and W. Olthuis, Meurement Science for Engineers. Kogan Page Science, 2004.

[129] G. Wolterink, A. Umrani, S. Martijn, R. Sanders, and G. Krijnen, "3DPrinted Calorimetric Flow Sensor," in Proceedings of IEEE Sensors, 2020 , to be published.

[130] X. Aeby, R. v. Dommelen, and D. Briand, "Fully FDM 3D Printed Flexible Capacitive and Resistive Transducers," 2019 20th International Conference on Solid-State Sensors, Actuators and Microsystems \& Eurosensors XXXIII (TRANSDUCERS \& EUROSENSORS XXXIII), no. June, pp. 2440-2443, 2019.

[131] M. Mohammadizadeh, I. Fidan, M. Allen, and A. Imeri, "Creep behavior analysis of additively manufactured fiber-reinforced components," International Journal of Advanced Manufacturing Technology, vol. 99, no. 5-8, pp. 1225-1234, 2018

[132] K. V. Niaza, F. S. Senatov, A. Stepashkin, N. Y. Anisimova, and M. V. Kiselevsky, "Long-Term Creep and Impact Strength of Biocompatible 3D-Printed PLA-Based Scaffolds," Nano Hybrids and Composites, vol. 13, pp. 15-20, 2017.

[133] M. Schouten, B. Prakken, R. Sanders, and G. Krijnen, "Linearisation of a 3D printed flexible tactile sensor based on piezoresistive sensing," Proceedings of IEEE Sensors, vol. 2019-Octob, 2020.

[134] D. Coleman, M. Khalid, and X. Tan, "Temperature-compensation of 3D-printed polymer-based strain gauge," PROCEEDINGS OF SPIE, no. March 2019, p. 20, 2019.

[135] H. T. Banks, "A brief review of some approaches to hysteresis in viscoelastic polymers," Nonlinear Analysis, Theory, Methods and Applications, vol. 69, no. 3, pp. 807-815, 2008.

[136] J. Shintake, E. Piskarev, S. H. Jeong, and D. Floreano, "Ultrastretchable Strain Sensors Using Carbon Black-Filled Elastomer Composites and Comparison of Capacitive Versus Resistive Sensors," Advanced Materials Technologies, vol. 3, no. 3, pp. 1-8, 2018.

[137] D. Kosmas, M. Schouten, and G. Krijnen, "Hysteresis Compensation of 3D Printed Sensors by a Power Law Model with Reduced Parameters," in FLEPS 2020 - IEEE International Conference on Flexible and Printable Sensors and Systems, Proceedings, 2020, to be published.

[138] V. Hassani, T. Tjahjowidodo, and T. N. Do, "A survey on hysteresis modeling, identification and control," Mechanical Systems and Signal Processing, vol. 49, no. 1-2, pp. 209-233, 2014. [Online]. Available: http://dx.doi.org/10.1016/j.ymssp.2014.04.012

[139] M. Schouten, D. Kosmas, and G. Krijnen, "Hysteresis Compensation of 3D Printed Sensors by a Power Law Model for Various input signals," Proceedings of IEEE Sensors, vol. 2020-Octob, 2020, to be published.

[140] I. Mayergoyz, "The Classical Preisach Model of Hysteresis," in Mathematical Models of Hysteresis and Their Applications. Elsevier, 2003, ch. 1, pp. 1-63.

[141] K. Kuhnen, "Modelling, identification, and compensation of complex hysteretic and $\log (\mathrm{t})$-type creep nonlinearities," Control and Intelligent Systems, vol. 33, no. 2, pp. 134-147, 2005.

[142] T. Kalmár-Nagy, D. Bernardini, B. Carboni, and W. Lacarbonara "Quantifying rate dependence of hysteretic systems," Procedia Engineering, vol. 199, pp. 1447-1453, 2017. [Online]. Available: http://dx.doi.org/10.1016/j.proeng.2017.09.483

[143] M. Biggio, A. Oliveri, F. Stellino, M. Parodi, and M. Storace, "A circuit model of hysteresis and creep," IEEE Transactions on Circuits and Systems II: Express Briefs, vol. 62, no. 5, pp. 501-505, 2015.
[144] J. Gan, Z. Mei, X. Chen, Y. Zhou, and M. F. Ge, "A modified Duhem model for rate-dependent hysteresis behaviors," Micromachines, vol. 10, no. 10, 2019.

[145] K. Kuhnen, "Modeling, identification and compensation of complex hysteretic nonlinearities: A modified prandtl-ishlinskii approach," $E u$ ropean Journal of Control, vol. 9, no. 4, pp. 407-418, 2003.

[146] A. Oliveri, F. Stellino, G. Caluori, M. Parodi, and M. Storace, "OpenLoop Compensation of Hysteresis and Creep Through a Power-Law Circuit Model," IEEE Transactions on Circuits and Systems I: Regular Papers, vol. 63, no. 3, pp. 413-422, 2016.

[147] J. F. Christ, N. Aliheidari, P. Pötschke, and A. Ameli, "Bidirectional and stretchable piezoresistive sensors enabled by multimaterial 3D printing of carbon nanotube/thermoplastic polyurethane nanocomposites," Polymers, vol. 11, no. 1, 2018

[148] M. Schouten, R. Sanders, and G. Krijnen, "3D printed flexible capacitive force sensor with a simple micro-controller based readout," Proceedings of IEEE Sensors, vol. 2017-Decem, no. 3, pp. 1-3, 2017.

[149] M. Ntagios, H. Nassar, A. Pullanchiyodan, W. T. Navaraj, and R. Dahiya, "Robotic Hands with Intrinsic Tactile Sensing via 3D Printed Soft Pressure Sensors," Advanced Intelligent Systems, no. October, p. 1900080, 2019.

[150] K. Li, H. Wei, W. Liu, H. Meng, P. Zhang, and C. Yan, "3D printed stretchable capacitive sensors for highly sensitive tactile and electrochemical sensing," Nanotechnology, vol. 29, no. 18, 2018.

[151] B. Chou, J. S. Park, and W. S. Kim, "3D printed inductor designs decorated with silver nano ink," 2015 IEEE Nanotechnology Materials and Devices Conference, NMDC 2015, pp. 1-2, 2016.

[152] M. Kisic, N. Blaz, L. Zivanov, and M. Damnjanovic, "Elastomer based force sensor fabricated by 3D additive manufacturing," AIP Advances, vol. 10, no. 1, pp. 1-5, 2020. [Online]. Available: https://doi.org/10.1063/1.5130065

[153] S. Y. Wu, C. Yang, W. Hsu, and L. Lin, "RF wireless lc tank sensors fabricated by 3D additive manufacturing," 2015 Transducers - 2015 18th International Conference on Solid-State Sensors, Actuators and Microsystems, TRANSDUCERS 2015, pp. 2208-2211, 2015.

[154] — , "3D-printed microelectronics for integrated circuitry and passive wireless sensors," Microsystems and Nanoengineering, vol. 1, no. June, pp. 1-9, 2015

[155] S. Krachunov and A. J. Casson, "3D Printed Dry EEG Electrodes," Sensors (Basel, Switzerland), vol. 16, no. 10, 2016.

[156] K. Elgeneidy, G. Neumann, M. Jackson, and N. Lohse, "Directly printable flexible strain sensors for bending and contact feedback of soft actuators," Frontiers Robotics AI, vol. 5, no. FEB, pp. 1-14, 2018.

[157] Y. Yang, Y. Chen, Y. Li, Z. Wang, and Y. Li, "Novel Variable-Stiffness Robotic Fingers with Built-In Position Feedback," Soft Robotics, vol. 4 , no. 4, pp. 338-352, 2017

[158] A. Manero, P. Smith, J. Sparkman, M. Dombrowski, D. Courbin, A. Kester, I. Womack, and A. Chi, "Implementation of 3D printing technology in the field of prosthetics: Past, present, and future," International Journal of Environmental Research and Public Health, vol. 16, no. 9, 2019.

[159] A. Zolfagharian, A. Kaynak, and A. Kouzani, "Closed-loop 4D-printed soft robots," Materials \& Design, vol. 188, p. 108411, 2020. [Online]. Available: https://doi.org/10.1016/j.matdes.2019.108411

[160] T. J. Wallin, J. Pikul, and R. F. Shepherd, "3D printing of soft robotic systems," Nature Reviews Materials, vol. 3, no. 6, pp. 84-100, 2018. [Online]. Available: http://dx.doi.org/10.1038/s41578-018-0002-2

[161] S. Li, H. Zhao, and R. F. Shepherd, "Flexible and stretchable sensors for fluidic elastomer actuated soft robots," MRS Bulletin, vol. 42, no. 2 , pp. 138-142, 2017.

[162] G. Stano and G. Percoco, "Design , 3D printing and characterization of a soft actuator with embedded strain sensor," 2020 IEEE International Symposium on Medical Measurements and Applications (MeMeA), pp. $5-10,2020$.

[163] B. Shih, C. Christianson, K. Gillespie, S. Lee, J. Mayeda, Z. Huo, and M. T. Tolley, "Design considerations for 3D printed, soft, multimaterial resistive sensors for soft robotics," Frontiers Robotics AI, vol. 6, no. APR, pp. 1-12, 2019 